\title{
To Cooperate or Not? An Analysis of Complementary Product Pricing in Green Supply Chain
}

\author{
Jie Wei ${ }^{1}$, Wen Wang ${ }^{2}$, Sang-Bing Tsai ${ }^{3,4, *(\mathbb{D})}$ and Xiaoli Yang ${ }^{5, *}$ \\ 1 School of Economics and Management, Hebei University of Technology, Tianjin 300401, China; \\ wei@hebut.edu.cn \\ 2 Business School, Nankai University, Tianjin 300071, China; ivywang@mail.nankai.edu.cn \\ 3 Zhongshan Institute, University of Electronic Science and Technology, Zhongshan 528400, China \\ 4 Research Center for Environment and Sustainable Development of China Civil Aviation, Civil Aviation \\ University of China, Tianjin 300300, China \\ 5 Tianjin Social Sciences, Tianjin Academy of Social Science, Tianjin 300191, China \\ * Correspondence: sangbing@hotmail.com (S.-B.T.); Yangxiaoli1001@126.com (X.Y.)
}

Received: 6 March 2018; Accepted: 18 April 2018; Published: 2 May 2018

check for updates

\begin{abstract}
This paper investigates the green supply chain pricing problem when two manufacturers sell complementary products to one retailer. Considering the manufacturers' cooperation or noncooperation strategies, we first give the centralized pricing model as a benchmark. According to market power among the supply chain, we analyze two types of supply chains: supplier-led type where the green driving factor comes from the suppliers and retailer-led type where the core member retailer leads the green supply chain. We then give two decentralized pricing models through considering strategic cooperation between two manufacturers and different structures. Corresponding closed-form expressions for equilibrium pricing strategies are established. Finally, many valuable managerial results are acquired through comparing the profits and equilibrium decisions of these models. Our paper shows that consumers are indifferent as to who is the leader of the two echelons when the manufacturers adopt non-cooperative action; the two complementary products get the same optimal wholesale/retail prices, maximum retail margins, and maximum demands regardless of the manufacturers' cooperation or noncooperation strategies.
\end{abstract}

Keywords: green supply chain; complementary products; supply chain leadership; cooperation pricing; sustainable pricing; sustainability

\section{Introduction}

Green production has become a prevalent and expanding field for its significant role in environmental and economic sustainability. Both practitioners and researchers pay attention to the green product problem to lower environment damage and remain profit at the same time [1-3]. Nowadays, product green level is not to be ignored by organizations as regulations and laws are becoming increasingly rigorous. Companies such as Apple, are working with their upstream manufacturers to redesign the production procedure as well as the product itself for the sake of environment and sustainability. As the product core designer, Apple sets the green product goal, and its suppliers coordinate with each other to reduce the use of poisonous metal and increase the manufacture material recycling (http:/ /iphone.tgbus.com/news/class/201701/20170101091221.shtml). Looking at the other side of the green story, from the perspective of the suppliers who sell complementary products to the core retailer, they face problems of pricing their own component and interacting with their peers. Another practical example of green choice is in the house renovation business. When Noritz provides an energy efficient water heater, Chicago Furnace also sells environment friendly 
faucets with water-saving outlet options (Contractor Magazine. Oct 2017, Vol. 64 Issue 10, p43.). This case shows that, in the end product market, firms also confront the pricing issue and counterpart firm relationship when providing green complementary products.

From the above cases, we detect that the market power is distributed differently in varying supply chains. In the first case, the upstream manufacturers have weaker market power compared to the buyer company Apple who retails to the market. Thus, the retailer is the leader, and we call this supply chain retailer-led type. In the second case, all manufacturers of household supplies have more market power than the buyer, i.e. the contractor who retail to the end customers. We call this type of supply chain, where the manufacturers are leaders, manufacturer-led type. As the ability of a firm to profitably raise the market price of a product over marginal cost, market power leads to the leadership of a member in the supply chain. The market power determined leadership of the channel members will affect their pricing orders. The product relationship (substitutable or complementary) also influences their pricing strategies. Product pricing is of vital importance for its direct influence to firm profits and corporate survival. Manufacturers and retailers usually pursue a pricing strategy to establish an optimum price with current profit maximization.

The practices discussed above naturally lead to our study of the pricing problem considering supply chain leadership. Many studies [4-7] have considered the impacts of market powers in supply chain management. In a single product or substitutable products supply chain, dominant manufacturers or retailers often use their strengths to gain concessions from their counterparts, leaving them in vulnerable situations with little profits. However, it is unclear if this forceful approach is efficient in a complementary products supply chain. As we know, in complementary products market, a firm will benefit from the thriving sales of their counterpart firm. Moreover, cooperation among the manufacturers and/or retailers may prove more effective at producing ongoing benefits for both the parties. Many examples can be listed where firms agree to adopt the cooperation alliance with the intention to benefit from unique advantages of their counterparts. For example, SBC communications and HP announced cooperation alliance for integrated IT and Telecom managed services; Apple Inc. and HP.com announced a cooperation alliance to deliver an HP-branded digital music player based on Apple's iPod [8].

In this paper, we consider a scenario where two manufacturers wholesale two complementary products to a common retailer who then retails them to consumers, similar to the above examples of Apple suppliers and the firms of house supplies. For more real-world examples that fit the scenario considered in this paper, please refer to [9]. The main purpose of this paper is to study the manufacturers' decisions of adopting cooperation or noncooperation action and their influences on the channel members' profits, the complementary products' optimal wholesale/retail prices. Specifically, our paper addresses the following four general problems:

1. In a decentralized supply chain, for the complementary products manufacturers, how effective is the cooperative action at improving their profits?

2. How do the two manufacturers' cooperative/non-cooperative actions influence their profits and the supply chain leadership structures (manufacturer-led or retailer-led)?

3. What are the two manufacturers' best actions (cooperation or noncooperation) under different supply chain leadership structures?

4. When the retailer has more power, should the retailer induce the manufacturers to adopt one specific relationship (cooperative or non-cooperative)?

To address these problems, as a benchmark to compare channel decisions under different scenarios, a centralized model is firstly established, namely, one entity aims to maximize the whole supply chain performance. Secondly, two decentralized scenarios are considered where the two manufacturers perform cooperation action. Finally, in Section 6, we comprehensively compare among the analytic results obtained in this paper where the two manufacturers adopt cooperative action and the results obtained in [10] where the two manufacturers adopt non-cooperative action. 
The remainder of this paper is given as follows. Section 2 gives the literature review. In Section 3 , we summarize our main results and contribution. Section 4 introduces problem description and notations. Section 5 addresses the pricing models and the analytical results. Managerial implications are acquired in Section 5. Section 6 gives the conclusion and some extensions for future research.

\section{Literature Review}

There are many studies concerning product pricing. Among these studies, some of them have considered the optimal pricing of single product or substitutable products (e.g., [7,11-14]). Choi [4] formulated three types of game models to study the optimal pricing of substitutable products in a supply chain with two manufacturers and one retailer. Haruvy et al. [15] considered two scenarios with a two-stage pricing format. For the first scenario, the firm does not commit to the second-stage price. For the second setting, the firm makes a binding commitment to a second-stage price. Li et al. [16] considered the inventory control and dynamic pricing for a stochastic inventory system with perishable products. A detailed review of these studies and others can be found in Chan et al. [17].

In recent years, many researchers have considered the pricing problem of complementary products (e.g., [18,19]). For example, Yin [20] studied how demand conditions (i.e., the form of the demand function and demand uncertainty) drive coalition formation among complementary suppliers. Wang [9] studied decentralized production-pricing of complementary products and their implications to supply chain performance. Dong et al. [21] investigated factors of product line pricing in a supply chain where a manufacturer sells two substitutable or complementary products to a retailer. Wei et al. [10] formulated decentralized pricing models for two complementary products through considering firms' market powers where the manufacturers adopt non-cooperative action. None of these papers studied the cooperative pricing problem of the manufacturers who produce the complementary products.

The study of the pricing game of cooperative manufacturers is not farfetched. In recent literature, it has become a norm to include the case of cooperation alliance. Many global strategy researchers are advocating firms to explore cooperation alliance with other firms and in some cases, even with their competitors (Mukhopadhyay et al. [19]). Examples of real-world manufacturer alliances in supply chains abound. For example, Greene [22] presented several instances of alliances between component manufacturers in the semiconductor industry (e.g., SMIC, a chip manufacturing company, and IMEC, a research company, formed an alliance selling to Texas Instruments). Moreover, retailers encourage cooperation between suppliers with the intent to convert difficult suppliers into supportive suppliers through cooperation, which provides opportunities for the sharing of good practices and experiences between suppliers ( $\mathrm{Li}$ et al. [23]). This paper provides valuable managerial guidance for retailers who sell complementary products and for manufacturers who produce functionally complementary products under different channel structures.

\section{Main Results and Contribution}

To our best knowledge, no research has studied green complementary product pricing considering the following two aspects together: (1) the channel leadership between the manufacturers and retailer; and (2) the manufacturers' cooperative pricing action. Our research is related to the study by Wei et al. [10] as it is the only one which considers the pricing decisions of two complementary products in a two-echelon supply chain by considering different market powers. This study extends the study by Wei et al. [10] to address the impact of the two manufacturers' cooperation alliance on pricing decision for the entire supply chain, the two manufacturers and the retailer under different channel structures. Unlike the studies of Mukhopadhyay et al. [19] and Wei et al. [10], this paper focuses on the market powers between the upstream and downstream firms and the manufacturers' pricing strategies together.

This work formulates three game models and obtains their analytic results. We not only compare the analytic results obtained in this paper, but also compare them with the results obtained in 
Wei et al. [10]. Some new and interesting results are obtained. For example, the two manufacturers' strategies of cooperation and noncooperation do not affect the two complementary products' optimal wholesale/retail prices, maximum retail margins, and maximum demands. Regardless of who is the Stackelberg-leader in the two-echelon channel, the two complementary products will have equal optimal retail prices when two manufacturers adopt non-cooperative action. Although the retailer achieves the same retail margins for the two complementary products when the retailer is channel leader which is independent of the two manufacturers' cooperative and non-cooperative actions, the retailer can get higher profit when the two manufacturers adopt cooperative action.

\section{Manufacturer/Retailer-Led Models and Analysis}

We consider a supply chain with one retailer and two manufacturers (Manufacturer 1 and Manufacturer 2). Manufacturer $i$ (he) makes product $i$ with unit production $\operatorname{cost} c_{i}$ and wholesales it to the common retailer at unit price $w_{i}$, the common retailer (she) then sells the product $i$ with unit retail price $p_{i}, i=1,2$. Products 1 and 2 are complementary and constrained under the same Green Partner Standards for further assemble or final consumption. Besides, as the market scenario used in Mukhopadhyay et al. [15], we assume there are three types of consumers (Type 1, Type 2 and Type 3) in the market. Type 1 only purchases Product 1, Type 2 needs Products 1 and 2, and Type 3 only buys Product 2. This scenario can be characterized by the real case from the computer industry, for more details see Mukhopadhyay et al. [19]. Similar to Mukhopadhyay et al. [19], we consider the similar model scenario and use the linear function to model the demands.

The demand functions are assumed to be linear with self-and cross-price sensitivities. Type 1's demand for Product 1 is:

$$
D_{11}\left(p_{1}\right)=a_{1}-\beta_{1} p_{1}
$$

Type 3's demand for Product 2 is:

$$
D_{23}\left(p_{2}\right)=a_{2}-\beta_{2} p_{2}
$$

Type 2's demands for Products 1 and 2 are, respectively, given as follows:

$$
\begin{aligned}
& D_{11}\left(p_{1}\right)=a-\beta_{11} p_{1}-\beta_{12} p_{2} \\
& D_{23}\left(p_{2}\right)=a-\beta_{22} p_{2}-\beta_{21} p_{1}
\end{aligned}
$$

where parameter $a_{1}$ denotes Type 1's potential demand for Product 1, $a_{2}$ is Type 3's potential demand for Product 2, and $a$ is the potential demand for Products 1 and 2 from Type 2. The parameters $\beta_{1}, \beta_{2}, \beta_{11}$ and $\beta_{22}$ are self-price sensitivities of each product's potential demand to its own price. $\beta_{12}$ and $\beta_{21}$ are cross-price sensitivities.

Assumption. The self and cross-price parameters are all nonnegative, $\beta_{1}, \beta_{2}, \beta_{11}$ and $\beta_{22}$ are larger than $\beta_{12}$ and $\beta_{21}$.

The assumption means that each product's potential demand is more sensitive to the changes of its own price than to that of its complementary product, which is consistent with the practice.

The aggregate demand for Product 1, namely, the sum of demands for Product 1 from Type 1 and Type 2, is expressed as

$$
D_{1}\left(p_{1}, p_{2}\right)=a_{1}+a-\left(\beta_{1}+\beta_{11}\right) p_{1}-\beta_{12} p_{2}
$$

The aggregate demand of Product 2 is

$$
D_{2}\left(p_{1}, p_{2}\right)=a_{2}+a-\left(\beta_{2}+\beta_{22}\right) p_{2}-\beta_{21} p_{1}
$$


The profits of Manufacturer $1\left(\pi_{m 1}\left(w_{1}\right)\right)$, Manufacturer $2\left(\pi_{m 2}\left(w_{2}\right)\right)$, the retailer $\left(\pi_{r}\left(p_{1}, p_{2}\right)\right)$, and the whole supply chain $\left(\pi_{c}\left(p_{1}, p_{2}\right)\right)$ are as follows,

$$
\begin{gathered}
\pi_{m 1}\left(w_{1}\right)=\left(w_{1}-c_{1}\right)\left[a_{1}+a-\left(\beta_{1}+\beta_{11}\right) p_{1}-\beta_{12} p_{2}\right] \\
\pi_{m 2}\left(w_{2}\right)=\left(w_{2}-c_{2}\right)\left[a_{2}+a-\left(\beta_{2}+\beta_{22}\right) p_{2}-\beta_{21} p_{1}\right] \\
\pi_{r}\left(p_{1}, p_{2}\right)=\sum_{i=1}^{2}\left(p_{i}-w_{i}\right) D_{i}\left(p_{1}, p_{2}\right) \\
=\left(p_{1}-w_{1}\right)\left[a_{1}+a-\left(\beta_{1}+\beta_{11}\right) p_{1}-\beta_{12} p_{2}\right]+\left(p_{2}-w_{2}\right)\left[a_{2}+a-\left(\beta_{2}+\beta_{22}\right) p_{2}-\beta_{21} p_{1}\right] \\
\pi_{c}\left(p_{1}, p_{2}\right)=\pi_{m 1}\left(w_{1}\right)+\pi_{m 2}\left(w_{2}\right)+\pi_{r}\left(p_{1}, p_{2}\right) \\
=\left(p_{1}-c_{1}\right)\left[a_{1}+a-\left(\beta_{1}+\beta_{11}\right) p_{1}-\beta_{12} p_{2}\right]+\left(p_{2}-w_{c}\right)\left[a_{2}+a-\left(\beta_{2}+\beta_{22}\right) p_{2}-\beta_{21} p_{1}\right]
\end{gathered}
$$

where the subscripts $m_{1}, m_{2}, r$ and $c$ represent Manufacturer 1, Manufacturer 2, the retailer, and the whole supply chain, respectively.

We first formulate the centralized decision (CD) model as a benchmark. Then, we establish two Stackelberg game models where the two manufacturers are cooperative. (1) MC model: The two manufacturers have more powers than the retailer, and two manufacturers form an alliance to optimize their total profits; (2) RC model: The retailer's market power is bigger than those of two manufacturers, and the two manufacturers also form an alliance to optimize their total profits.

\subsection{Model}

In the CD model, the pricing decisions of manufacturers and the retailer are fully coordinated, the three firms have the same objective to optimize their total profit. The CD model is formulated as

$$
\max _{\left(p_{1}, p_{2}\right)} \pi_{c}\left(p_{1}, p_{2}\right)
$$

Proposition 1. The optimal retail prices $p_{c 1}^{*}$ and $p_{c 2}^{*}$ in the $C D$ model are given as follows

$$
\begin{aligned}
& p_{c 1}^{*}=\frac{A_{1} A_{4}-A_{2} A_{5}}{A_{3} A_{4}-A_{5}^{2}} \\
& p_{c 2}^{*}=\frac{A_{2} A_{3}-A_{1} A_{5}}{A_{3} A_{4}-A_{5}^{2}}
\end{aligned}
$$

where $A_{1}, A_{2}, \cdots, A_{5}$ are constants defined in Appendix $A$.

Proof. Using Equation (10), one can easily prove that the profit $\pi_{c}\left(p_{1}, p_{2}\right)$ is jointly concave in $p_{1}$ and $p_{2}$. Through setting the first order partial derivatives of $\pi_{c}\left(p_{1}, p_{2}\right)$ to $p_{1}$ and $p_{2}$ to zero and solving them simultaneously, we can get the results of Proposition 1.

\subsection{The MC Model}

MC model characterizes a market where one retailer retails two complementary products (e.g., computer hardware and software) made by two different manufacturers. The two manufacturers have more powers than that of the retailer, and the two manufacturers form an alliance to optimize 
their total profits considering their interdependence. When the two manufacturers form an alliance to maximize their total profits, the MC model is formulated as

$$
\left\{\begin{array}{l}
\max _{w_{1}, w_{2}}\left[\pi_{m 1}\left(w_{1}, p_{1}^{*}\left(w_{1}, w_{2}\right), p_{2}^{*}\left(w_{1}, w_{2}\right)\right)+\pi_{m 2}\left(w_{2}, p_{1}^{*}\left(w_{1}, w_{2}\right), p_{2}^{*}\left(w_{1}, w_{2}\right)\right)\right] \\
p_{1}^{*}\left(w_{1}, w_{2}\right), p_{2}^{*}\left(w_{1}, w_{2}\right) \text { are given as follows } \\
\max _{\left(p_{1}, p_{2}\right)} \pi_{r}\left(p_{1}, p_{2}\right)
\end{array}\right.
$$

Thus, we have the channel members' optimal decisions in the MC model as follows:

Proposition 2. In the MC model, the optimal decisions of the two manufacturers ( $w_{m c 1}^{*}$ and $w_{m c 2}^{*}$ ) and the common retailer $\left(p_{m c 1}^{*}\right.$ and $\left.p_{m c 2}^{*}\right)$ are given as

$$
\begin{gathered}
w_{m c 1}^{*}=\frac{C_{4} C_{5}-C_{1} C_{6}}{C_{4}^{2}-C_{2} C_{6}} \\
w_{m c 2}^{*}=\frac{C_{1} C_{4}-C_{2} C_{5}}{C_{4}^{2}-C_{2} C_{6}} \\
p_{m c 1}^{*}=B_{1}+B_{2} \frac{C_{4} C_{5}-C_{1} C_{6}}{C_{4}^{2}-C_{2} C_{6}}+B_{3} \frac{C_{1} C_{4}-C_{2} C_{5}}{C_{4}^{2}-C_{2} C_{6}} \\
p_{m c 2}^{*}=B_{4}+B_{5} \frac{C_{1} C_{4}-C_{2} C_{5}}{C_{4}^{2}-C_{2} C_{6}}+B_{6} \frac{C_{4} C_{5}-C_{1} C_{6}}{C_{4}^{2}-C_{2} C_{6}}
\end{gathered}
$$

where $B_{1}, B_{2}, \cdots, B_{6}$ and $C_{1}, C_{2}, \cdots, C_{6}$ are constants defined in Appendix $A$.

Proof. The proof of Propositions 2 and 3 are given in Appendixs C and D.

\subsection{The RC Model}

The RC model characterizes the market where the powerful retailer retails two complementary products (e.g., DVD content and players), and the two manufacturers form an alliance to optimize their total profits considering their interdependence. Take WalMart and Amazon for example, the retailer dominants its supplier (e.g., content providers and player suppliers). In these real scenarios, the retailer as the leader will play Stackelberg game with the manufacturers who are the followers. The RC model is established as follows

$$
\left\{\begin{array}{l}
\max _{\left(p_{1}, p_{2}\right)} \pi_{r}\left(p_{1}, p_{2}, w_{1}^{*}\left(p_{1}, p_{2}\right), w_{2}^{*}\left(p_{1}, p_{2}\right)\right) \\
w_{1}^{*}\left(p_{1}, p_{2}\right), w_{2}^{*}\left(p_{1}, p_{2}\right) \text { are obtained as follows } \\
\max _{\left(w_{1}, w_{2}\right)}\left(\pi_{m 1}\left(w_{1}\right)+\pi_{m 2}\left(w_{2}\right)\right)
\end{array}\right.
$$

Thus, we have the channel members' optimal decisions in the RC model as follows:

Proposition 3. In the RC model, the optimal decisions of the common retailer $\left(p_{r c 1}^{*}, p_{r c 2}^{*}\right)$ and of the two manufacturers $\left(w_{r c 1}^{*}\right.$ and $w_{r c 2}^{*}$ ) are expressed as follows

$$
\begin{gathered}
p_{r c 1}^{*}=\frac{H_{1} H_{5}-H_{3} H_{4}}{H_{2} H_{5}-H_{3} H_{3}} \\
p_{r c 2}^{*}=\frac{H_{2} H_{4}-H_{1} H_{3}}{H_{2} H_{5}-H_{3} H_{3}} \\
w_{r c 1}^{*}=F_{1}-F_{2} p_{r c 1}^{*}-F_{3} p_{r c 2}^{*}
\end{gathered}
$$




$$
w_{r c 2}^{*}=F_{4}-F_{5} p_{r c 2}^{*}-F_{6} p_{r c 1}^{*}
$$

where $H_{1}, H_{2}, \cdots, H_{5}$ are constants defined in Appendix $B$.

\section{Managerial Analysis}

In this section, we not only compare the analytic results obtained in this paper, but also compare them with the results obtained in Wei et al. [10]. Namely, the results of RS Bertrand and MS Bertrand models where the two manufacturers do not form an alliance. We rewrite the RS Bertrand model and the MS Bertrand model in Wei et al. [10] as RNC model and MNC model, respectively, in the following discussion.

We set the parameters used in our models as $a_{1}=a_{2}, c_{1}=c_{2}, \beta_{1}=\beta_{2}, \beta_{11}=\beta_{22}$ and $\beta_{12}=\beta_{21}$ to ensure that the comparison of our models is possible and to gain more useful managerial insights. The literature (e.g., Tsay and Agrawal [13]) tells us that the parameter asymmetry generates problems when we compare the model results.

\subsection{Comparison and Analysis of the Model Solutions}

In this subsection, the equilibrium solutions of five models are established when the parameters of two complementary products are symmetric. With the comparison and analysis of the equilibrium solutions, we obtain many managerial insights. We assume that the two manufacturers agree to reach the agreement on the split of their total profit in the MC and RC models, namely, manufacturer $i$ gains the profit from product $i$. The results with symmetric parameters are summarized in the following theorem.

Theorem 1. When the parameters of two complementary products are symmetric, the equilibrium solutions of the five models are summarized as shown in Table 1, and the maximum profits of every channel members and the total channel can be summarized as shown in Table 2, where $\alpha=a_{1}+a=a_{2}+a, c=c_{1}=c_{2}$, $\beta=\beta_{1}+\beta_{11}=\beta_{2}+\beta_{22}$, and $\gamma=\beta_{12}=\beta_{21}$.

Remark 1. To assure two manufacturers have an interest to take part in the sales activities, we assume that the marginal contribution of manufacturer $i$ has to be nonnegative, i.e., $w_{i}-c>0$. Moreover, to assure there is a nonnegative demand of product $i$, the condition $\alpha-(\beta+\gamma) c>0$ must hold. Therefore, for the rest of this paper, we assume that these conditions are satisfied.

Table 1. Equilibrium solutions.

\begin{tabular}{cccccc}
\hline & CD Model & MNC Model & MC Model & RC Model & RNC Model \\
\hline$w_{1}^{*}$ & $N / A$ & $\frac{\alpha+\beta c}{2 \beta+\gamma}$ & $\frac{\alpha+\beta c}{2 \beta+\gamma}$ & $\frac{\alpha+3(\beta+\gamma) c}{4(\beta+\gamma)}$ & $\frac{\alpha+3(\beta+\gamma) c}{2(2 \beta+\gamma)}$ \\
$w_{2}^{*}$ & $N / A$ & $\frac{\alpha+\beta c}{2 \beta+\gamma}$ & $\frac{\alpha+\beta c}{2 \beta+\gamma}$ & $\frac{\alpha+3(\beta+\gamma) c}{4(\beta+\gamma)}$ & $\frac{\alpha+3(\beta+\gamma) c}{2(2 \beta+\gamma)}$ \\
$p_{1}^{*}$ & $\frac{\alpha+(\beta+\gamma) c}{2(\beta+\gamma)}$ & $\frac{(\beta+\gamma) \beta c+\alpha(3 \beta+2 \gamma)}{2(\beta+\gamma)(2 \beta+\gamma)}$ & $\frac{3 \alpha+\beta c}{4(\beta+\gamma)}$ & $\frac{3 \alpha+(\beta+\gamma) c}{4(\beta+\gamma)}$ & $\frac{(\beta+\gamma) \beta c+\alpha(3 \beta+2 \gamma)}{2(\beta+\gamma)(2 \beta+\gamma)}$ \\
$p_{2}^{*}$ & $\frac{\alpha+(\beta+\gamma) c}{2(\beta+\gamma)}$ & $\frac{(\beta+\gamma) \beta c+\alpha(3 \beta+2 \gamma)}{2(\beta+\gamma)(2 \beta+\gamma)}$ & $\frac{3 \alpha+\beta c}{4(\beta+\gamma)}$ & $\frac{3 \alpha+(\beta+\gamma) c}{4(\beta+\gamma)}$ & $\frac{(\beta+\gamma) \beta c+\alpha(3 \beta+2 \gamma)}{2(\beta+\gamma)(2 \beta+\gamma)}$ \\
$m_{1}^{*}$ & $N / A$ & $\frac{\beta(\alpha-(\beta+\gamma) c)}{2(\beta+\gamma)(2 \beta+\gamma)}$ & $\frac{\alpha-\beta c}{4(\beta+\gamma)}$ & $\frac{\alpha-(\beta+\gamma) c}{2(\beta+\gamma)}$ & $\frac{\alpha-(\beta+\gamma) c}{2(\beta+\gamma)}$ \\
$m_{2}^{*}$ & $N / A$ & $\frac{\beta(\alpha-(\beta+\gamma) c)}{2(\beta+\gamma)(2 \beta+\gamma)}$ & $\frac{\alpha-\beta c}{4(\beta+\gamma)}$ & $\frac{\alpha-(\beta+\gamma) c}{2(\beta+\gamma)}$ & $\frac{\alpha-\beta+\gamma) c}{2(\beta+\gamma)}$ \\
$D_{1}^{*}$ & $\frac{\alpha-(\beta+\gamma) c}{2}$ & $\frac{\beta(\alpha-(\beta+\gamma) c)}{2(2 \beta+\gamma)}$ & $\frac{\alpha-\beta c}{4}$ & $\frac{\alpha-(\beta+\gamma) c}{4}$ & $\frac{\beta(\alpha-(\beta+\gamma) c)}{2(2 \beta+\gamma)}$ \\
$D_{2}^{*}$ & $\frac{\alpha-(\beta+\gamma) c}{2}$ & $\frac{\beta(\alpha-(\beta+\gamma) c)}{2(2 \beta+\gamma)}$ & $\frac{\alpha-\beta c}{4}$ & $\frac{\alpha-(\beta+\gamma) c}{4}$ & $\frac{\beta(\alpha-(\beta+\gamma) c)}{2(2 \beta+\gamma)}$ \\
\hline
\end{tabular}


Table 2. Firms' maximum profits.

\begin{tabular}{cccccc}
\hline & CD Model & MNC Model & MC Model & RC Model & RNC Model \\
\hline$\pi_{m 1}^{*}$ & $N / A$ & $\frac{\beta(\alpha-(\beta+\gamma) c)^{2}}{2(2 \beta+\gamma)^{2}}$ & $\frac{(\alpha-(\beta+2 \gamma) c)(\alpha-\beta c)}{8(\beta+\gamma)}$ & $\frac{(\alpha-(\beta+\gamma) c)^{2}}{16(\beta+\gamma)}$ & $\frac{\beta(\alpha-(\beta+\gamma) c)^{2}}{4(2 \beta+\gamma)^{2}}$ \\
$\pi_{m 2}^{*}$ & $N / A$ & $\frac{\beta(\alpha-(\beta+\gamma) c)^{2}}{2(2 \beta+\gamma)^{2}}$ & $\frac{(\alpha-(\beta+2 \gamma) c)(\alpha-\beta c)}{8(\beta+\gamma)}$ & $\frac{(\alpha-(\beta+\gamma) c)^{2}}{16(\beta+\gamma)}$ & $\frac{\beta(\alpha-(\beta+\gamma) c)^{2}}{4(2 \beta+\gamma)^{2}}$ \\
$\pi_{r}^{*}$ & $N / A$ & $\frac{\beta^{2}(\alpha-(\beta+\gamma))^{2}}{2(\beta+\gamma)(2 \beta+\gamma)^{2}}$ & $\frac{(\alpha-\beta c)^{2}}{8(\beta+\gamma)}$ & $\frac{(\alpha-(\beta+\gamma) c)^{2}}{4(\beta+\gamma)}$ & $\frac{\beta(\alpha-(\beta+\gamma) c)^{2}}{2(2 \beta+\gamma)(\beta+\gamma)}$ \\
$\pi_{t}^{*}$ & $\frac{(\alpha-(\beta+\gamma) c)^{2}}{2(\beta+\gamma)}$ & $\frac{\beta(\alpha-(\beta+\gamma) c)^{2}(3 \beta+2 \gamma)}{2(\beta+\gamma)(2 \beta+\gamma)^{2}}$ & $\frac{(\alpha-\beta c)(3 \alpha-3 \beta c-4 \gamma c)}{8(\beta+\gamma)}$ & $\frac{3(\alpha-(\beta+\gamma) c)^{2}}{8(\beta+\gamma)}$ & $\frac{\beta(\alpha-(\beta+\gamma) c)^{2}(3 \beta+2 \gamma)}{2(2 \beta+\gamma)^{2}(\beta+\gamma)}$ \\
\hline \multicolumn{7}{c}{ Note: $\pi_{t}^{*}$ denotes the total channel profit. }
\end{tabular}

Table 1 indicates that the two complementary products will have equal optimal wholesale/retail prices, retail margins, and maximum demands in the MNC model, and the same results also appear in the $\mathrm{MC}, \mathrm{RC}, \mathrm{RNC}$, and CD models. Interestingly, the retailer will charge the same optimal retail prices in MNC and RNC models. Moreover, it is also possible to verify that the optimal wholesale price and optimal retail price of each product in the MNC model are larger than those in the MC model, respectively. The same results also hold for both the RNC model and the RC model. It shows that the noncooperation between the manufacturers enhances the two complementary products' optimal wholesale/retail prices in the MS and RS game scenarios. From Tables 1 and 2, the following insights can be obtained.

(I) The two manufacturers' strategies of cooperation and noncooperation do not affect the two complementary products' optimal wholesale/retail prices, maximum retail margins, and maximum demands. This is also holds for the market powers between the two echelons.

(II) Regardless of who is the Stackelberg-leader in the two-echelon channel, the two complementary products will have equal optimal retail prices when two manufacturers adopt non-cooperative action, while the optimal wholesale prices in RNC model are lower than those in MNC model. Therefore, the leader gets a larger share of the constant-sum total channel profit. Moreover, consumers are indifferent as to who is the channel leader of the two echelons, when only the MNC and RNC models are considered.

(III) No matter which the two manufacturers perform between cooperative and non-cooperative actions in RS game case, the retailer will achieve the same retail margins of the two complementary products, while the maximum demands in RNC model are lower than those in RC model. This means that the two manufacturers' cooperative action is more profitable for the retailer who is channel leader.

(IV) In MS game scenario, the two complementary products' optimal retail/wholesale prices in MNC model are larger than those in MC model. This means that the two manufacturers' non-cooperative strategy will increase the two complementary products' optimal retail/wholesale prices and will damage the consumers' revenues because of the higher optimal retail prices. The same result is also valid in RS game scenario. Thus, the two manufacturers' cooperative action is more profitable for the consumers which is independent of who is the channel leader.

(V) The lowest retail prices of two complementary products appear in the CD model, followed by the MC model, RC model, and RNC/MNC models. It means that the demands achieve the largest quantities in the CD model, followed by the MC model, RC model, and RNC/MNC models.

(VI) Manufacturer $i$ can make a larger profit in MNC model than in RNC model, while the retailer can make a larger profit in RNC model than in MNC model. This implies that the leader of the two echelons can get a larger share of the fixed total channel profit when the two manufacturers adopt the non-cooperative action. Moreover, the total channel profit in MNC model equals to that in RNC model. 
(VII) It is interesting to see that demand substitution does not affect the maximum demands of the two complementary products when the two manufacturers are channel leaders and they adopt cooperative action.

\subsection{Parameters' Sensitivity Analysis}

In this subsection, we perform some sensitivity analysis on some key parameters with the intent to examine the influences on model solutions and profits by numerical approach. Some managerial insights are derived from these analyses.

Discussion 1. Tables 3-6 summarize the effects of symmetric production cost and market base changes on prices, demands, retail margins, and profit levels.

Table 3. Effect of market base changes on price, margin and demand.

\begin{tabular}{cccccc}
\hline & CD Model & MNC Model & MC Model & RC Model & RNC Model \\
\hline$\frac{\partial w_{i}^{*}}{\partial \alpha}$ & $N / A$ & $\frac{1}{2 \beta+\gamma}$ & $\frac{1}{2(\beta+\gamma)}$ & $\frac{1}{4(\beta+\gamma)}$ & $\frac{1}{2(2 \beta+\gamma)}$ \\
$\frac{\partial p_{i}^{*}}{\partial \alpha}$ & $\frac{1}{2(\beta+\gamma)}$ & $\frac{3 \beta+2 \gamma}{2(\beta+\gamma)(2 \beta+\gamma)}$ & $\frac{3}{4(\beta+\gamma)}$ & $\frac{3}{4(\beta+\gamma)}$ & $\frac{3 \beta+2 \gamma}{2(\beta+\gamma)(2 \beta+\gamma)}$ \\
$\frac{\partial m_{i}^{*}}{\partial \alpha}$ & $N / A$ & $\frac{\beta}{2(\beta+\gamma)(2 \beta+\gamma)}$ & $\frac{1}{4(\beta+\gamma)}$ & $\frac{1}{2(\beta+\gamma)}$ & $\frac{1}{2(\beta+\gamma)}$ \\
$\frac{\partial D_{i}^{*}}{\partial \alpha}$ & $\frac{1}{2}$ & $\frac{\beta}{2(2 \beta+\gamma)}$ & $\frac{1}{4}$ & $\frac{1}{4}$ & $\frac{\beta}{2(2 \beta+\gamma)}$ \\
\hline
\end{tabular}

Table 4. Effect of symmetric market base changes on profits.

\begin{tabular}{ccccc}
\hline & MNC Model & MC Model & RC Model & RNC Model \\
\hline$\frac{\partial \pi_{m i}^{*}}{\partial \alpha}$ & $\frac{\beta(\alpha-(\beta+\gamma) c)}{(2 \beta+\gamma)^{2}}$ & $\frac{\alpha-(\beta+\gamma) c}{4(\beta+\gamma)}$ & $\frac{\alpha-(\beta+\gamma) c}{8(\beta+\gamma)}$ & $\frac{\beta(\alpha-(\beta+\gamma) c)}{2(2 \beta+\gamma)^{2}}$ \\
$\frac{\partial \pi_{r}^{*}}{\partial \alpha}$ & $\frac{\beta^{2}(\alpha-(\beta+\gamma) c)}{(\beta+\gamma)(2 \beta+\gamma)^{2}}$ & $\frac{\alpha-\beta c}{4(\beta+\gamma)}$ & $\frac{\alpha-(\beta+\gamma) c}{2(\beta+\gamma)}$ & $\frac{\beta(\alpha-(\beta+\gamma) c)}{(2 \beta+\gamma)(\beta+\gamma)}$ \\
\hline
\end{tabular}

Table 5. Effect of production cost changes on price, demand and margin.

\begin{tabular}{cccccc}
\hline & CD Model & MNC Model & MC Model & RC Model & RNC Model \\
\hline$\frac{\partial w_{i}^{*}}{\partial c}$ & $N / A$ & $\frac{\beta}{2 \beta+\gamma}$ & $\frac{\beta}{2(\beta+\gamma)}$ & $\frac{3}{4}$ & $\frac{3 \beta+\gamma}{2(2 \beta+\gamma)}$ \\
$\frac{\partial p_{i}^{*}}{\partial c}$ & $\frac{1}{2}$ & $\frac{\beta}{2(2 \beta+\gamma)}$ & $\frac{\beta}{4(\beta+\gamma)}$ & $\frac{1}{4}$ & $\frac{\beta}{2(2 \beta+\gamma)}$ \\
$\frac{\partial m_{i}^{*}}{\partial c}$ & $N / A$ & $-\frac{\beta}{2(2 \beta+\gamma)}$ & $-\frac{\beta}{4(\beta+\gamma)}$ & $-\frac{1}{2}$ & $-\frac{1}{2}$ \\
$\frac{\partial D_{i}^{*}}{\partial c}$ & $-\frac{\beta+\gamma}{2}$ & $-\frac{\beta(\beta+\gamma)}{2(2 \beta+\gamma)}$ & $-\frac{\beta}{4}$ & $-\frac{\beta+\gamma}{4}$ & $-\frac{\beta(\beta+\gamma)}{2(2 \beta+\gamma)}$ \\
\hline
\end{tabular}

Table 6. Effect of production cost changes on profits.

\begin{tabular}{ccccc}
\hline & MNC Model & MC Model & RC Model & RNC Model \\
\hline$\frac{\partial \pi_{m i}^{*}}{\partial c}$ & $-\frac{\beta(\beta+\gamma)(\alpha-(\beta+\gamma) c)}{(2 \beta+\gamma)^{2}}$ & $-\frac{\alpha(\beta+\gamma)-\beta(\beta+2 \gamma) c}{4(\beta+\gamma)}$ & $-\frac{\alpha-(\beta+\gamma) c}{8}$ & $-\frac{\beta(\beta+\gamma)(\alpha-(\beta+\gamma) c)}{2(2 \beta+\gamma)^{2}}$ \\
$\frac{\partial \pi_{r}^{*}}{\partial c}$ & $-\frac{\beta^{2}(\alpha-(\beta+\gamma) c)}{(2 \beta+\gamma)^{2}}$ & $-\frac{\beta(\alpha-\beta c)}{4(\beta+\gamma)}$ & $-\frac{\alpha-(\beta+\gamma) c}{2}$ & $-\frac{\beta(\alpha-(\beta+\gamma) c)}{2 \beta+\gamma}$ \\
\hline
\end{tabular}

The following sensitivity analysis of parameter $\alpha$ can be obtained from Tables 3 and 4 .

(1.1) $\frac{\partial p_{i}^{*}}{\partial \alpha}>\frac{\partial w_{i}^{*}}{\partial \alpha}>0, i=1,2$ in MNC, MC, RNC, and RC models, which means that the increases of market base $\alpha$ enhance the two complementary products' optimal retail prices $\left(p_{1}^{*}, p_{2}^{*}\right)$ and optimal wholesale prices $\left(w_{1}^{*}, w_{2}^{*}\right)$, and the changes in the optimal retail prices are larger than those in the optimal wholesale prices. Moreover, one can see that $\frac{\partial p_{i}^{*}}{\partial \alpha}>0$ is also valid in the CD model. 
(1.2) The optimal wholesale prices are most sensitive to the market base change in MNC model, followed by the MC, RNC and the RC models, which tell us that, as the increases of market base, the increases of the wholesale prices when the manufacturers are the leaders are larger than those when the retailer is the leader, and the increases in the optimal wholesale prices when the manufacturers adopt non-cooperative action are larger than those when the manufacturers adopt cooperation alliance in the RS and MS game cases.

(1.3) The changes of market base have the same effect on the optimal retail prices in RC and MC models regardless of who is the channel leader, and the same results appear in RNC and MNC models. Moreover, the changes of market base have the highest effects on the optimal retail prices in MNC/RNC models, followed by MC/RC models, and CD model. It shows that, as the increases of market base, the increases in the optimal retail prices when the manufacturers adopt non-cooperative action are larger than those when the manufacturers perform cooperation alliance in MS and RS game cases.

(1.4) The market base changes have the same effects on the retail margins in RNC and RC models regardless of the manufacturers' actions. Moreover, the effects of the market base change on the retail margins achieve the largest values in RNC/RC models, followed by MC model, and MNC model. It shows that as the market base increases, the increase in the retail margins when the retailer is the leader is larger than that when the manufacturers are the leaders, and the increase in the retail margins when the manufacturers adopt cooperative action is larger than that when the manufacturers adopt non-cooperative action in RS game scenario.

(1.5) The market base changes have the same effects on the maximum demands in MC and RC models regardless of who is the leader of the two echelons, and the same results appear in the RNC and MNC models. Moreover, the market base changes have the largest effects on the maximum demands in CD model, followed by the MC/RC models, and MNC/RNC models. It shows that, as the market base increases, the increases in the maximum demands in CD model are larger than those in the decentralized models, and the increases in the maximum demands when the manufacturers adopt cooperative action are larger than those when the manufacturers adopt non-cooperative action in MS and RS game scenarios.

(1.6) We can verify that $\frac{\partial \pi_{m i}^{*}}{\partial \alpha}>0, i=1,2$ is valid in MNC, MC, RNC, and RC models. We can also see that the effects of market base changes on the manufacturers' profits in $\mathrm{MC}$ model are larger than those in RC model, and the effects of market base changes on the manufacturers' profits in MNC model are larger than those in RNC model. It shows that the manufacturers' profits are more sensitive to the market base change when the manufacturers are the leaders.

(1.7) We can verify that $\frac{\partial \pi_{r}^{*}}{\partial \alpha}>0$ is valid in MNC, MC, RNC, and RC models. We can also see that the effect of the market base changes on the retailer's profit when the manufacturers adopt cooperative action is larger than that when the manufacturers adopt non-cooperative action in MS game scenario, and the result is valid in RS game scenario. It shows that the manufacturers' actions affect the effects of the market base change on the retailer's profit.

Following the above Results (1.1)-(1.7), the following insights can be obtained as follows.

(VIII)Both the optimal retail/wholesale prices increase as the market base increases, and the increases in the optimal retail prices are larger than those in the optimal wholesale prices. This is independent of the two manufacturers' cooperative and non-cooperative strategies. Moreover, the two complementary products' total demands increase as the increases of market base. All the channel firms benefit from the increases of the two complementary products' market bases.

(IX) The two manufacturers' profits are more sensitive to the market base changes when they are the leaders than when they are the followers regardless whether they adopt the non-cooperative or cooperative actions. Moreover, the two manufacturers' profits are more sensitive to the market base changes when they adopt the cooperative action than when they adopt the non-cooperative action in both MS and RS game scenarios. 
(X) The market base changes have the same effects on the maximum demands in MC and RC models regardless of who is the leader of the two echelons. The same result is valid in MNC and RNC models.

The following sensitivity analysis of parameter $c$ can be obtained from Tables 5 and 6 .

(2.1) The optimal wholesale prices have the most sensitivity to the production cost changes in RC model, then the RNC model, MNC model and the MC model, which means that, as the production cost increases, the increases in the optimal wholesale prices when the retailer is the leader are larger than those when the retailer is the follower. Moreover, the increases in the optimal wholesale prices when the manufacturers adopt non-cooperative action are larger than those when the manufacturers adopt cooperative action in MS game scenario, however the result in RS game scenario is the reverse.

(2.2) The effects of the production cost changes on the optimal retail prices in MNC and RNC models are the same regardless of who is the leader of the two echelons. However, the increases in the optimal retail prices in RC model are larger than those in MC model.

(2.3) $\frac{\partial w_{i}^{*}}{\partial c}>\frac{\partial p_{i}^{*}}{\partial c}>0, i=1,2$ is valid in MNC, MC, RNC, and RC models, which means that market base increases increase the optimal retail/wholesale prices. Notice that the increases of the optimal retail prices are smaller than those of optimal wholesale prices, and the retail margin decreases as the market base $\alpha$ increases $\left(\frac{\partial m_{i}}{\partial c}<0, i=1,2\right)$. Therefore, although the wholesale prices decrease as the production costs are reduced, the retail margins increase. The reason is that there is only one common retailer at the retail level, i.e., no competition at the retail level.

(2.4) The effects of the production cost changes on the retail margins in RNC and RC models are the same regardless of the manufacturers' actions. However, the retail margins are more sensitive to the production cost changes in MNC model than in MC model.

(2.5) The effects of the production cost changes on the maximum demands in MNC and RNC models are the same regardless of who is the leader of the two echelons. Moreover, the effects of production cost changes on the maximum demands in CD model are larger than those in the RC model, then the MNC/RNC models, and the MC model.

(2.6) $\frac{\partial \pi_{m i}^{*}}{\partial \alpha}<0, i=1,2$ and $\frac{\partial \pi_{r}^{*}}{\partial \alpha}<0$ are valid in the MC, RNC, MNC, and the RC models. Moreover, one can see that the manufacturers' profits have more sensitivity to the production cost changes in the MNC model than in the RNC model, whereas the retailer's profit has more sensitivity to the production cost changes in the RNC model than in the MNC model.

Following these Results (2.1)-(2.6), the following insights can be given as follows.

(XI) No matter which the manufacturers perform cooperation action and noncooperation action and who becomes the Stackelberg-leader in the two-echelon channel, the optimal retail/wholesale prices will rise when the production cost increases, and the increase in the optimal wholesale prices is larger than that in the optimal retail prices, whereas the increase has a negative effect on two complementary products' demand quantities.

(XII) All channel members as well as the consumers will lose when the production cost increases; in other words, all channel members can benefit from the production cost savings in terms of both the increased margins and demands.

(XIII)The effects of the production cost change on the optimal retail prices are the same regardless of who is the leader of the two echelons when two manufacturers perform non-cooperative strategy. However, the effects of the production cost change on the optimal retail prices in RC model are larger than those in MC model.

(XIV)The effects of the production cost change on the retail margins in RNC and RC models are the same regardless of the manufacturers' actions. The effects of the production cost change on the retail margins when the manufacturers adopt cooperative action are larger than those when the manufacturers adopt non-cooperative action in MS game scenario. Moreover, the effects of the 
production cost changes on the retail margins when the retailer is the leader are larger than those when the manufacturers are the leaders regardless of the manufacturers' actions.

\section{Discussion 2. Analysis of $\beta$ and $\gamma$}

Here, we study how the optimal retail/wholesale prices, maximum demands, retail margins and the firms' profits are affected by the changes arising from self-price sensitivity $\beta$ and cross-price sensitivity $\gamma$ with numerical studies.

Figure 1a-f presents the changes of the optimal wholesale/retail prices, maximum demands, retail margins and firms' profits with parameter $\beta$, where the parameters' values are $\alpha=180, \gamma=0.3$, $c=25$ and $\beta \in\{0.5,0.6,0.7,0.8,0.9\}$. Figure $2 \mathrm{a}-\mathrm{f}$ presents the changes of the optimal wholesale/retail prices, maximum demands, retail margins and firms' profits with parameter $\gamma$, where the parameters' values are $\alpha=180, \gamma=0.3, c=25$ and $\beta \in\{0.4,0.5,0.6,0.7,0.8\}$.

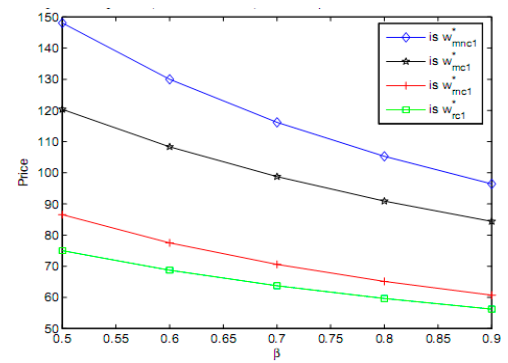

(a)

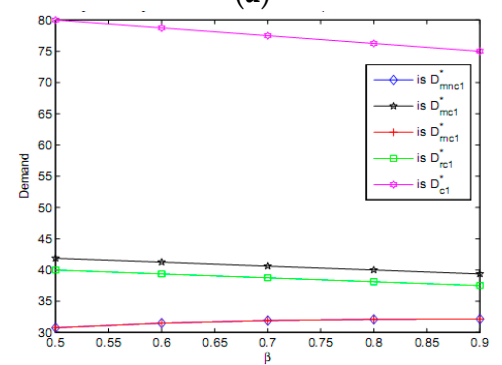

(c)

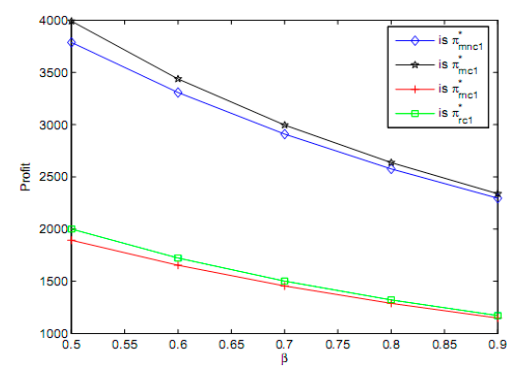

(e)

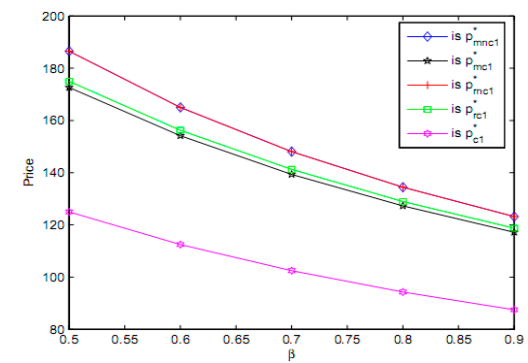

(b)

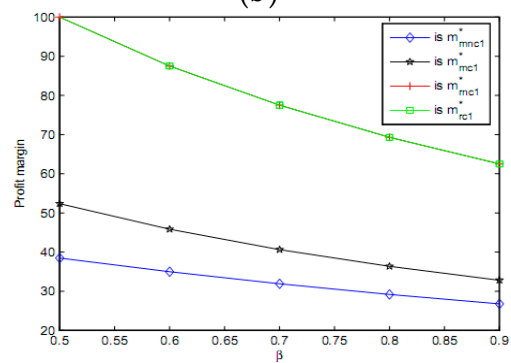

(d)

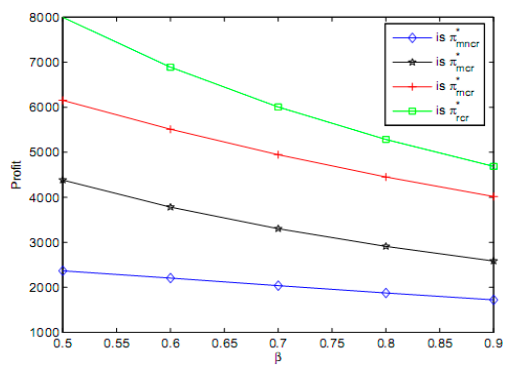

(f)

Figure 1. (a) Changes of optimal wholesale prices with $\beta$ in decentralized decision models; (b) changes of optimal retail prices with $\beta$ in five decision models; (c) changes of demand with $\beta$ in five models; (d) changes of profit margins with $\beta$ in decentralized models; (e) changes of Manufacturer 1's profit with $\beta$ in decentralized models; and (f) changes of retailer's profit with $\beta$ in decentralized models. 


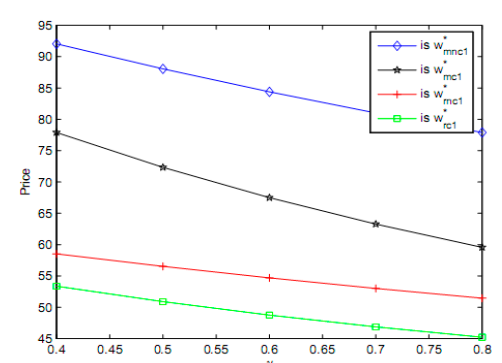

(a)

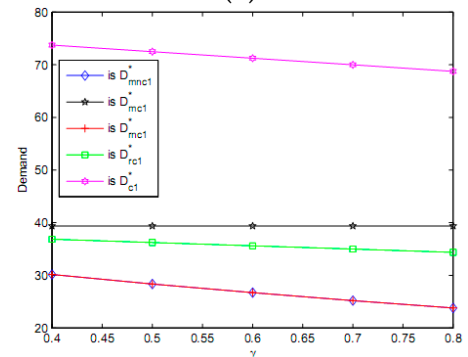

(c)

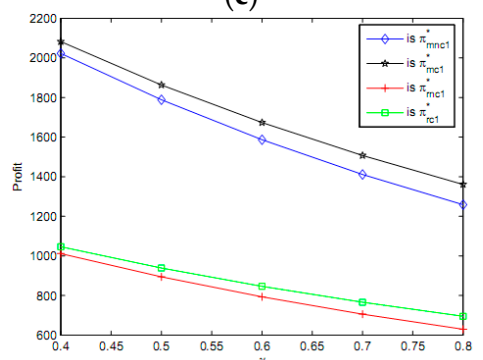

(e)

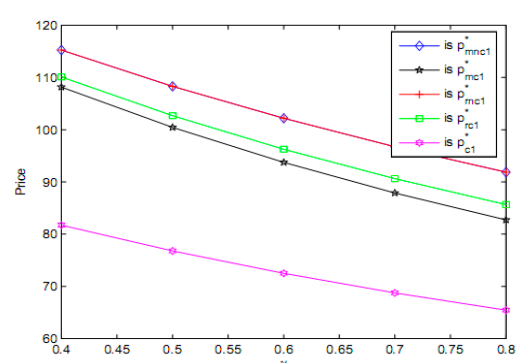

(b)

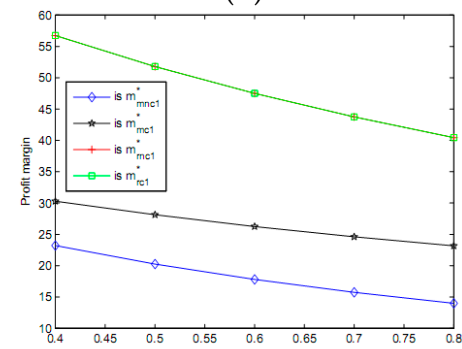

(d)

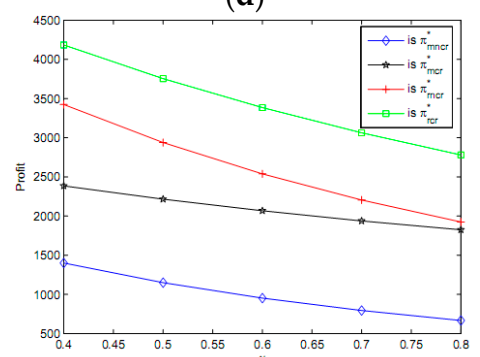

(f)

Figure 2. (a) Changes of wholesale prices with $\gamma$ in decentralized models; (b) changes of retail prices with $\gamma$ in five models; (c) changes of maximum demand with $\gamma$ in five models; (d) changes of profit margins with $\gamma$ in decentralized models; (e) changes of Manufacturer 1's profit with $\gamma$ in decentralized models; and (f) changes of retailer's profit with $\gamma$ in decentralized models.

The following results can be obtained from Figures 1 and 2:

(3.1) The optimal wholesale/retail prices, maximum demands, retail margins and firms' profits all drop with self-price sensitivity $\beta$ and cross-price sensitivity $\gamma$ in the five pricing game models. Moreover, the optimal retail prices of MS and RS game cases are almost indistinguishable when the manufacturers adopt the cooperative action.

(3.2) The maximum demands decrease as self-price sensitivity $\beta$ increases in MC, RC, and CD models, whereas the maximum demands increase as self-price sensitivity $\beta$ increases in MNC and RNC models. On the other hand, the maximum demands decrease as cross-price sensitivity $\gamma$ increases in $\mathrm{MNC}, \mathrm{RNC}, \mathrm{RC}$, and CD models, whereas the maximum demands remain unchanged as cross-price sensitivity $\gamma$ increases in MC model, which is consistent with Insight VII.

(3.3) The difference of the manufacturer $i$ 's profit in MNC and MC models is small, and the difference becomes more smaller as self-price sensitivity $\beta$ increases, and a similar result of the manufacturer $i$ 's profit appears in MNC and RNC models. On the other hand, the differences of the retailer's profit among the five pricing game models are obvious, although the differences will also become smaller as self-price sensitivity $\beta$ increases.

(3.4) The difference of the manufacturer $i$ 's profit in MNC and RNC models becomes more clearer as the cross-price sensitivity $\gamma$ increases, and a similar result of manufacturer $i$ 's profit appears in MNC and RNC models. On the other hand, the difference of the retailer's profits among the five 
pricing game models are also obvious, moreover the difference of the retailer's profits in MC and RNC models will become smaller as the cross-price sensitivity $\gamma$ increases.

From the above comparison Results (3.1)-(3.4), we have the following insight:

(XV) Regardless of the channel leadership and the two manufacturers' actions, the optimal wholesale/retail prices and firms' profits drop with self- and cross-price sensitivities.

\subsection{Numerical Example}

In this subsection, a numerical study is given and the parameters' values are as follows, $\alpha=180$, $\beta=0.7, \gamma=0.4$ and $c=25$. The numerical study results are expressed in Tables 7 and 8 .

Table 7. Optimal retail/wholesale prices in the five models.

\begin{tabular}{ccccccc}
\hline Decision Scenario & $p_{\mathbf{1}}^{*}$ & $\boldsymbol{w}_{\mathbf{1}}^{*}$ & $\boldsymbol{p}_{\mathbf{1}}^{*}-\boldsymbol{w}_{\mathbf{1}}^{*}$ & $\boldsymbol{p}_{\mathbf{2}}^{*}$ & $\boldsymbol{w}_{\mathbf{2}}^{*}$ & $\boldsymbol{p}_{\mathbf{2}}^{*}-\boldsymbol{w}_{\mathbf{2}}^{*}$ \\
\hline CD model & 136.68 & 109.72 & 26.96 & 136.68 & 109.72 & 26.96 \\
MNC model & 126.70 & 89.77 & 36.93 & 126.70 & 89.77 & 36.93 \\
MC model & 136.68 & 67.36 & 69.32 & 136.68 & 67.36 & 69.32 \\
RC model & 128.98 & 59.66 & 69.32 & 128.98 & 59.66 & 69.32 \\
RNC model & 94.32 & N/A & N/A & 94.32 & N/A & N/A \\
\hline
\end{tabular}

Table 8. Maximum profits in the five models.

\begin{tabular}{ccccc}
\hline Decision Scenario & $\boldsymbol{\pi}_{\boldsymbol{m} \mathbf{1}}+\boldsymbol{\pi}_{\boldsymbol{m} \mathbf{2}}+\boldsymbol{\pi}_{\boldsymbol{r}}$ & $\boldsymbol{\pi}_{\boldsymbol{m} \mathbf{1}}$ & $\boldsymbol{\pi}_{\boldsymbol{m} \boldsymbol{2}}$ & $\boldsymbol{\pi}_{\boldsymbol{r}}$ \\
\hline CD model & $6.6232 \times 10^{3}$ & $2.5122 \times 10^{3}$ & $2.5122 \times 10^{3}$ & $1.5987 \times 10^{3}$ \\
MNC model & $8.2635 \times 10^{3}$ & $2.6314 \times 10^{3}$ & $2.6314 \times 10^{3}$ & $3.0007 \times 10^{3}$ \\
MC model & $6.6232 \times 10^{3}$ & $1.2561 \times 10^{3}$ & $1.2561 \times 10^{3}$ & $4.1110 \times 10^{3}$ \\
RC model & $7.9283 \times 10^{3}$ & $1.3214 \times 10^{3}$ & $1.3214 \times 10^{3}$ & $5.2855 \times 10^{3}$ \\
RNC model & $1.0571 \times 10^{3}$ & $\mathrm{~N} / \mathrm{A}$ & $\mathrm{N} / \mathrm{A}$ & $\mathrm{N} / \mathrm{A}$ \\
\hline
\end{tabular}

The following results can be obtained from Tables 7 and 8:

(4.1) The smallest retail prices obtained in the CD model, followed by the MC, RC, and the RNC/MNC models, and the smallest wholesale prices obtained in the RC model, then the RNC, MC, and the MNC models. Moreover, the retailer's margin of product $i$ in the RC model equals that in the RNC model, and the retailer's retail margin of product $i$ obtains the largest value in the RC/RNC models, followed by the MC, and MNC models.

(4.2) Manufacturer $i$ has the largest profit in the MC model, then the MNC, RC, and the RNC models. Unlike manufacturer $i$, the retailer gets its largest profit in the RC model, followed by the RNC, $\mathrm{MC}$ and the MNC models. Moreover, the largest value of firms' total profit appears in the $\mathrm{CD}$ model, followed by the MC, RC and the MNC/RNC models.

Following Analyses (4.1) and (4.2), the following insights can be obtained as follows.

(XVI) Both firms and consumers benefit from the two manufacturers' cooperative action in the decentralized scenarios.

(XVII) The retailer when acting as a channel leader should make the two manufacturers perform cooperative action.

(XVIII) The whole industry as well as consumers will obtain the largest profits in the centralized channel structure.

Remark 2. In the real world, the total profit obtained by the two manufacturers when they perform cooperation action are allocated to them according to their bargaining powers. However, Table 8 tells us that manufacturer $i$ gaining profit from product $i$ is a simple and feasible way to allocate the profit of cooperation alliance. 


\section{Concluding Remarks and Future Research}

We present the pricing decisions of complementary products in a supply chain including two manufacturers and one retailer under centralized and decentralized decision cases respectively. As a benchmark, the centralized decision model is first established and its solutions are given. We then establish the decentralized pricing models (e.g., the MC and RC models) by considering manufacturers' pricing strategies. Under different game structures that differ in the Stackelberg leader, the equilibrium solutions are given. Finally, we perform the comparison analysis of firms profits and optimal decisions by using analytical method and numerical studies when parameters are symmetrical. Some new managerial insights are obtained.

The main contributions are summarized as follows. First, two decentralized pricing models are formulated considering who is the leader of the two echelons when the manufacturers perform cooperation strategy, which extends the current research on the pricing of complementary products. Second, the analytical equilibrium solutions of these models are obtained. Third, through numerical approach, some new insights are obtained: (1) No matter which actions the two manufacturers perform in MS and RS games, cooperation or noncooperation, the two complementary products will get the same optimal wholesale/retail prices, maximum margins, and maximum demands. (2) Regardless of who becomes the Stackelberg-leader in the two-echelon channel, two complementary products will get the same optimal retail prices when two manufacturers perform non-cooperative action. Moreover, consumers are indifferent as to who is the leader of the two echelons, when only the MNC and RNC models are considered. (3) All channel members as well as consumers benefit from two manufacturers' cooperative action in decentralized pricing scenarios.

We list some possible extensions to this paper. First, the linear and price-sensitive demand functions are used in our models, and only one decision variable-price-is considered. One can establish the models with non-linear demand functions and study other marketing mix variables (e.g., promotion and advertising). Second, our models assume there are only one retailer at the retail level, one can study the market with two retailers who sell two complementary products, respectively. Third, this work assumes the demands are deterministic, however, the pricing decisions of this supply chain with a random demand would be a significant analysis. Fourth, this paper assumes all channel members have complete information on demand and cost. It is also interesting to consider the pricing decision under information asymmetry. Finally, our results show that no matter which actions the two manufacturers perform, the decentralized pricing models are inferior to the centralized model. Thus, further investigating performance-improving mechanisms for our models is also worthwhile.

Author Contributions: Jie Wei wrote the paper; Wen Wang, Sang-Bing Tsai and Xiaoli Yang contributed cases and ideas; and Sang-Bing Tsai and Xiaoli Yang provided advice on the revision.

Acknowledgments: We gratefully acknowledge the support of National Natural Science Foundation of China, No. 71371186. Moreover, this work was supported by the Zhongshan City Science and Technology Bureau Project (No. 2017B1015). The authors also wish to express their sincerest thanks to the editors and anonymous referees for their constructive comments and suggestions on the paper.

Conflicts of Interest: The authors declare no conflicts of interest.

\section{Appendix A. Notations for Decision Models in MC Model}

$$
\begin{gathered}
A_{1}=a_{1}+a+c_{1} \beta_{1}+c_{1} \beta_{11}+c_{2} \beta_{21} \\
A_{2}=a_{2}+a+c_{2} \beta_{2}+c_{2} \beta_{22}+c_{1} \beta_{12} \\
A_{3}=2\left(\beta_{1}+\beta_{11}\right) \\
A_{4}=2\left(\beta_{2}+\beta_{22}\right) \\
A_{5}=\left(\beta_{12}+\beta_{21}\right)
\end{gathered}
$$




$$
\begin{gathered}
B_{1}=\frac{\left(\beta_{12}+\beta_{21}\right)\left(a_{2}+a\right)-2\left(\beta_{2}+\beta_{22}\right)\left(a_{1}+a\right)}{\left(\beta_{12}+\beta_{21}\right)^{2}-4\left(\beta_{1}+\beta_{11}\right)\left(\beta_{2}+\beta_{22}\right)} \\
B_{2}=\frac{\left(\beta_{12}+\beta_{21}\right) \beta_{12}-2\left(\beta_{2}+\beta_{22}\right)\left(\beta_{1}+\beta_{11}\right)}{\left(\beta_{12}+\beta_{21}\right)^{2}-4\left(\beta_{1}+\beta_{11}\right)\left(\beta_{2}+\beta_{22}\right)} \\
B_{3}=\frac{\left(\beta_{12}-\beta_{21}\right)\left(\beta_{2}+\beta_{22}\right)}{\left(\beta_{12}+\beta_{21}\right)^{2}-4\left(\beta_{1}+\beta_{11}\right)\left(\beta_{2}+\beta_{22}\right)} \\
B_{4}=\frac{\left(\beta_{12}+\beta_{21}\right)\left(a_{1}+a\right)-2\left(\beta_{1}+\beta_{11}\right)\left(a_{2}+a\right)}{\left(\beta_{12}+\beta_{21}\right)^{2}-4\left(\beta_{1}+\beta_{11}\right)\left(\beta_{2}+\beta_{22}\right)} \\
B_{5}=\frac{\left(\beta_{12}+\beta_{21}\right) \beta_{21}-2\left(\beta_{2}+\beta_{22}\right)\left(\beta_{1}+\beta_{11}\right)}{\left(\beta_{12}+\beta_{21}\right)^{2}-4\left(\beta_{1}+\beta_{11}\right)\left(\beta_{2}+\beta_{22}\right)} \\
B_{6}=\frac{\left(\beta_{21}-\beta_{12}\right)\left(\beta_{1}+\beta_{11}\right)}{\left(\beta_{12}+\beta_{21}\right)^{2}-4\left(\beta_{1}+\beta_{11}\right)\left(\beta_{2}+\beta_{22}\right)} \\
B_{7}=a_{2}+a-\left(\beta_{2}+\beta_{22}\right) B_{4}-\beta_{21} B_{1}+\left(\beta_{2}+\beta_{22}\right) c_{2} B_{5}+\beta_{21} c_{2} B_{3} \\
B_{8}=2\left(\beta_{2}+\beta_{22}\right) B_{5}+2 \beta_{21} B_{3} \\
C_{1}=a_{1}+a-\left(\beta_{2}+\beta_{22}\right) B_{6}+\beta_{21} B_{2} \\
\left.C_{5}=a_{2}+a-\beta_{11}\right) B_{1}-\beta_{12} B_{4}+\left(\beta_{1}+\beta_{11}\right) c_{1} B_{2}+\beta_{12} c_{1} B_{6} \\
C_{2}=2\left(\beta_{1}+\beta_{11}\right) B_{2}+2 \beta_{12} B_{6} \\
C_{3}=\left(\beta_{1}+\beta_{11}\right) B_{3}+\beta_{12} B_{5} \\
C_{6}=2\left(\beta_{2}+\beta_{22}\right) B_{5}+2 \beta_{21} B_{3}
\end{gathered}
$$

\section{Appendix B. Notations for Decision Models in RC Model}

$$
\begin{gathered}
E_{1}=3\left(a_{1}+a\right)+\left(\beta_{1}+\beta_{11}\right) c_{1}+\frac{2 \beta_{21}\left(a_{2}+a\right)}{\beta_{2}+\beta_{22}}+\beta_{21} c_{2} \\
E_{2}=4\left(\beta_{1}+\beta_{11}\right)+\frac{2 \beta_{21}^{2}}{\beta_{2}+\beta_{22}} \\
E_{3}=3\left(\beta_{12}+\beta_{21}\right) \\
E_{4}=3\left(a_{2}+a\right)+\left(\beta_{2}+\beta_{22}\right) c_{2}+\frac{2 \beta_{12}\left(a_{1}+a\right)}{\beta_{1}+\beta_{11}}+\beta_{12} c_{1} \\
E_{5}=4\left(\beta_{2}+\beta_{22}\right)+\frac{2 \beta_{12}^{2}}{\beta_{1}+\beta_{11}} \\
F_{21}\left(a_{2}+a+c_{2}\left(\beta_{2}+\beta_{22}\right)+c_{1} \beta_{12}\right)-\left(\beta_{2}+\beta_{22}\right)\left(a_{1}+a+c_{1}\left(\beta_{1}+\beta_{11}\right)+c_{2} \beta_{21}\right) \\
\beta_{12} \beta_{21}-\left(\beta_{1}+\beta_{11}\right)\left(\beta_{2}+\beta_{22}\right)
\end{gathered}
$$




$$
\begin{gathered}
F_{4}=\frac{\beta_{12}\left(a_{1}+a+c_{1}\left(\beta_{1}+\beta_{11}\right)+c_{2} \beta_{21}\right)-\left(\beta_{1}+\beta_{11}\right)\left(a_{2}+a+c_{2}\left(\beta_{2}+\beta_{22}\right)+c_{1} \beta_{12}\right)}{\beta_{12} \beta_{21}-\left(\beta_{1}+\beta_{11}\right)\left(\beta_{2}+\beta_{22}\right)} \\
F_{5}=\frac{\beta_{12}^{2}-\left(\beta_{1}+\beta_{11}\right)\left(\beta_{2}+\beta_{22}\right)}{\beta_{12} \beta_{21}-\left(\beta_{1}+\beta_{11}\right)\left(\beta_{2}+\beta_{22}\right)} \\
F_{6}=\frac{\left(\beta_{1}+\beta_{11}\right)\left(\beta_{12}-\beta_{21}\right)}{\beta_{12} \beta_{21}-\left(\beta_{1}+\beta_{11}\right)\left(\beta_{2}+\beta_{22}\right)} \\
H_{1}=\left(1+F_{2}\right)\left(a_{1}+a\right)+F_{1}\left(\beta_{1}+\beta_{11}\right)+F_{6}\left(a_{2}+a\right)+F_{4} \beta_{21} \\
H_{2}=2\left(1+F_{2}\right)\left(\beta_{1}+\beta_{11}\right)+2 F_{6} \beta_{21} \\
H_{3}=F_{6}\left(\beta_{2}+\beta_{22}\right)+\left(F_{5}+1\right) \beta_{21}+F_{3}\left(\beta_{1}+\beta_{11}\right)+\left(1+F_{2}\right) \beta_{12} \\
H_{4}=\left(F_{5}+1\right)\left(a_{2}+a\right)+F_{4}\left(\beta_{2}+\beta_{22}\right)+F_{3}\left(a_{1}+a\right)+F_{1} \beta_{12} \\
H_{5}=2\left(F_{5}+1\right)\left(\beta_{2}+\beta_{22}\right)+2 F_{3} \beta_{12}
\end{gathered}
$$

\section{Appendix C. Proof of Proposition 2}

Given earlier decisions made by the two manufacturers are $w 1$ and $w 2$, respectively, we first derive the retailer's decisions as follows.

Proposition 2-1. In the MC model, given earlier decisions made by the two manufacturers are $w_{1}$ and $w_{2}$, respectively, the common retailer's optimal retail prices $p_{1}^{*}\left(w_{1}, w_{2}\right)$ and $p_{2}^{*}\left(w_{1}, w_{2}\right)$ are

$$
\begin{aligned}
& p_{1}^{*}\left(w_{1}, w_{2}\right)=B_{1}+B_{2} w_{1}+B_{3} w_{2} \\
& p_{2}^{*}\left(w_{1}, w_{2}\right)=B_{4}+B_{5} w_{2}+B_{6} w_{1}
\end{aligned}
$$

where $B_{1}, B_{2}, \cdots, B_{6}$ are constants defined in Appendix $B$.

Proof. From Equation (9), the first-order partial derivatives of $\pi_{r}\left(p_{1}, p_{2}\right)$ to $p_{1}$ and $p_{2}$ can be shown as

$$
\begin{aligned}
& \frac{\partial \pi_{r}\left(p_{1,}, p_{2}\right)}{\partial p_{1}}=a_{1}+a-2\left(\beta_{1}+\beta_{11}\right) p_{1}-\left(\beta_{12}+\beta_{21}\right) p_{2}+\left(\beta_{1}+\beta_{11}\right) w_{1}+\beta_{21} w_{2} \\
& \frac{\partial \pi_{r}\left(p_{1}, p_{2}\right)}{\partial p_{2}}=a_{2}+a-2\left(\beta_{2}+\beta_{22}\right) p_{2}-\left(\beta_{12}+\beta_{21}\right) p_{1}+\left(\beta_{2}+\beta_{22}\right) w_{2}+\beta_{12} w_{1}
\end{aligned}
$$

The second-order derivatives are acquired below to check the optimality

$$
\begin{gathered}
\frac{\partial^{2} \pi_{r}\left(p_{1,}, p_{2}\right)}{\partial p_{1}^{2}}=-2\left(\beta_{1}+\beta_{11}\right), \frac{\partial^{2} \pi_{r}\left(p_{1,}, p_{2}\right)}{\partial p_{2}^{2}}=-2\left(\beta_{2}+\beta_{22}\right) \\
\frac{\partial^{2} \pi_{r}\left(p_{1,} p_{2}\right)}{\partial p_{1} \partial p_{2}}=\frac{\partial^{2} \pi_{r}\left(p_{1,} p_{2}\right)}{\partial p_{2} \partial p_{1}}=-\left(\beta_{12}+\beta_{21}\right)
\end{gathered}
$$

We have a negative definite Hessian Matrix from Equations (A5) and (A6) and the assumption that the self-price sensitivities are greater than the cross-price sensitivities. Therefore, $\pi_{r}\left(p_{1}, p_{2}\right)$ is jointly concave in $p_{1}$ and $p_{2}$. By setting Equations (A3) and (A4) to zero and solving them simultaneously, we obtain Equations (A1) and (A2). Thus Proposition 2-1 is proved.

Having the information about the decisions of the common retailer, the two manufacturers would then use them to maximize their total profit $\pi_{m 1}+\pi_{m 2}$. So, we have the following result given as in Proposition 2-2. 
Proposition 2-2. In the MC model, the two manufacturers' optimal wholesale prices $w_{m c 1}^{*}$ and $w_{m c 2}^{*}$ can be given, respectively, as

$$
\begin{aligned}
& w_{m c 1}^{*}=\frac{C_{4} C_{5}-C_{1} C_{6}}{C_{4}^{2}-C_{2} C_{6}} \\
& w_{m c 2}^{*}=\frac{C_{1} C_{4}-C_{2} C_{5}}{C_{4}^{2}-C_{2} C_{6}}
\end{aligned}
$$

where $C_{1}, C_{2}, \cdots, C_{6}$ are constants defined in Appendix B.

Proof. It follows from Equations (7) and (8), Equations (A1) and (A2) that the first order partial derivatives of $\pi_{m 1}+\pi_{m 2}$ to $w_{1}$ and $w_{2}$ can be shown as

$$
\begin{aligned}
& \frac{\partial\left(\pi_{m 1}\left(w_{1}\right)+\pi_{m 2}\left(w_{2}\right)\right)}{\partial w_{1}}=C_{1}-C_{2} w_{1}-C_{4} w_{2} \\
& \frac{\partial\left(\pi_{m 1}\left(w_{1}\right)+\pi_{m 2}\left(w_{2}\right)\right)}{\partial w_{2}}=C_{5}-C_{6} w_{2}-C_{4} w_{1}
\end{aligned}
$$

It follows from Equations (A9) and (A10) that the second order partial derivatives are given below to check the optimality

$$
\begin{gathered}
\frac{\partial^{2}\left(\pi_{m 1}\left(w_{1}\right)+\pi_{m 2}\left(w_{2}\right)\right)}{\partial w_{1}^{2}}=-C_{2}<0, \frac{\partial^{2}\left(\pi_{m 1}\left(w_{1}\right)+\pi_{m 2}\left(w_{2}\right)\right)}{\partial w_{2}^{2}}=-C_{6}<0 \\
\frac{\partial^{2}\left(\pi_{m 1}\left(w_{1}\right)+\pi_{m 2}\left(w_{2}\right)\right)}{\partial w_{1} \partial w_{2}}=\frac{\partial^{2}\left(\pi_{m 1}\left(w_{1}\right)+\pi_{m 2}\left(w_{2}\right)\right)}{\partial w_{2} \partial w_{1}}=-C_{4}
\end{gathered}
$$

Using Equations (A11) and (A12) and the assumption that the self-price sensitivities are greater than the cross-price sensitivities, we know that $\pi_{m 1}+\pi_{m 2}$ is jointly concave in $w 1$ and $w 2$. Therefore, by setting Equations (A9) and (A10) to zero and solving them simultaneously, Equations (A7) and (A8) can be obtained. This proves Proposition 2-2.

Proposition 2-3. In the MC model, the common retailer's optimal retail prices $p_{m c 1}^{*}$ and $p_{m c 2}^{*}$ are given as

$$
\begin{aligned}
& p_{m c 1}^{*}=B_{1}+B_{2} \frac{C_{4} C_{5}-C_{1} C_{6}}{C_{4}^{2}-C_{2} C_{6}}+B_{3} \frac{C_{1} C_{4}-C_{2} C_{5}}{C_{4}^{2}-C_{2} C_{6}} \\
& p_{m c 2}^{*}=B_{4}+B_{5} \frac{C_{1} C_{4}-C_{2} C_{5}}{C_{4}^{2}-C_{2} C_{6}}+B_{6} \frac{C_{4} C_{5}-C_{1} C_{6}}{C_{4}^{2}-C_{2} C_{6}}
\end{aligned}
$$

where $B_{1}, B_{2}, \cdots, B_{6}$, and $C_{1}, C_{2}, \cdots, C_{6}$ are constants defined in Appendix $B$.

Proof. Through Propositions 2-1 and 2-2, Proposition 2-3 can be obtained.

With Propositions 2-2 and 2-3, Proposition 2 can be obtained.

\section{Appendix D. Proof of Proposition 3}

We first need to derive the two manufacturers' decisions. Without loss of generality, let $m_{i}$ be the retail margin of product $i$ enjoyed by the retailer, namely,

$$
p_{i}=w_{i}+m_{i}
$$

where $m_{i}>0, i=1,2$. 
Proposition 3-1. In the RC model, given earlier decisions $p_{1}$ and $p_{2}$ made by the common retailer, the two manufacturers' optimal wholesale prices $w_{1}^{*}\left(p_{1}, p_{2}\right)$ and $w_{2}^{*}\left(p_{1}, p_{2}\right)$ can be obtained respectively as

$$
\begin{aligned}
& w_{1}^{*}\left(p_{1}, p_{2}\right)=F_{1}-F_{2} p_{1}-F_{3} p_{2} \\
& w_{2}^{*}\left(p_{1}, p_{2}\right)=F_{4}-F_{5} p_{2}-F_{6} p_{1}
\end{aligned}
$$

where $F_{1}, F_{2}, \cdots, F_{6}$ are constants defined in Appendix $C$.

Proof. From Equations (7), (8) and (A15), the first order partial derivatives of $\pi_{m 1}\left(w_{1}\right)+\pi_{m 2}\left(w_{2}\right)$ with respect to $w_{1}$ and $w_{2}$ as

$$
\begin{aligned}
& \frac{\partial\left(\pi_{m 1}\left(w_{1}\right)+\pi_{m 2}\left(w_{2}\right)\right)}{\partial w_{1}}=a_{1}+a+\left(c_{1}-p_{1}-w_{1}\right)\left(\beta_{1}+\beta_{11}\right)+c_{2} \beta_{21}-\beta_{12} p_{2}-\beta_{21} w_{2} \\
& \frac{\partial\left(\pi_{m 1}\left(w_{1}\right)+\pi_{m 2}\left(w_{2}\right)\right)}{\partial w_{2}}=a_{2}+a+\left(c_{2}-p_{2}-w_{2}\right)\left(\beta_{2}+\beta_{22}\right)+c_{1} \beta_{12}-\beta_{21} p_{1}-\beta_{12} w_{1}
\end{aligned}
$$

Then we get

$$
\begin{gathered}
\frac{\partial^{2}\left(\pi_{m 1}\left(w_{1}\right)+\pi_{m 2}\left(w_{2}\right)\right)}{\partial w_{1}^{2}}=-2\left(\beta_{1}+\beta_{11}\right), \frac{\partial^{2}\left(\pi_{m 1}\left(w_{1}\right)+\pi_{m 2}\left(w_{2}\right)\right)}{\partial w_{2}^{2}}=-2\left(\beta_{2}+\beta_{22}\right) \\
\frac{\partial^{2}\left(\pi_{m 1}\left(w_{1}\right)+\pi_{m 2}\left(w_{2}\right)\right)}{\partial w_{1} \partial w_{2}}=\frac{\partial^{2}\left(\pi_{m 1}\left(w_{1}\right)+\pi_{m 2}\left(w_{2}\right)\right)}{\partial w_{2} \partial w_{1}}=-2\left(\beta_{12}+\beta_{21}\right)
\end{gathered}
$$

It follows from Equations (A20) and (A21) and the assumption that the self-price sensitivities are greater than the cross-price sensitivities that $\pi_{m 1}\left(w_{1}\right)+\pi_{m 2}\left(w_{2}\right)$ is jointly concave in $w_{1}$ and $w_{2}$. Therefore, setting Equations (A18) and (A19) to zero and solving them, Proposition 3-1 can be obtained.

Having the information about the decisions of the two manufacturers, the common retailer would then use them to maximize her profit. So, we have the following results given as in Proposition 3-2.

Proposition 3-2. In the RC model, the common retailer's optimal retail prices $p_{r c 1}^{*}$ And $p_{r c 2}^{*}$ are

$$
\begin{aligned}
& p_{r c 1}^{*}=\frac{H_{1} H_{5}-H_{3} H_{4}}{H_{2} H_{5}-H_{3} H_{3}} \\
& p_{r c 2}^{*}=\frac{H_{2} H_{4}-H_{1} H_{3}}{H_{2} H_{5}-H_{3} H_{3}}
\end{aligned}
$$

where $H_{1}, H_{2}, \cdots, H_{5}$ are constants defined in Appendix $C$.

Proof. From Equations (9), (A15)-(A17), the first order derivatives of $\pi_{r}\left(p_{1}, p_{2}\right)$ with respect to $p_{1}$ and $p_{2}$ can be shown as

$$
\begin{aligned}
& \frac{\partial \pi_{r}\left(p_{1}, p_{2}\right)}{\partial p_{1}}=H_{1}-H_{2} p_{1}-H_{3} p_{2} \\
& \frac{\partial \pi_{r}\left(p_{1}, p_{2}\right)}{\partial p_{2}}=H_{4}-H_{5} p_{2}-H_{3} p_{1}
\end{aligned}
$$

Then we get

$$
\begin{aligned}
& \frac{\partial^{2} \pi_{r}\left(p_{1}, p_{2}\right)}{\partial p_{1}^{2}}=-H_{2}, \frac{\partial^{2} \pi_{r}\left(p_{1}, p_{2}\right)}{\partial p_{2}^{2}}=-H_{5} \\
& \frac{\partial^{2} \pi_{r}\left(p_{1}, p_{2}\right)}{\partial p_{1} \partial p_{2}}=-H_{3}, \frac{\partial^{2} \pi_{r}\left(p_{1}, p_{2}\right)}{\partial p_{2} \partial p_{1}}=-H_{3}
\end{aligned}
$$


Using Equations (A26) and (A27) and the assumptions that the self-price sensitivities are greater than the cross-price sensitivities, we know that $\pi_{r}\left(p_{1}, p_{2}\right)$ is jointly concave in $p_{1}$ and $p_{2}$. Therefore, setting Equations (A24) and (A25) to zero and solving them simultaneously yields Equations (A22) and (A23); thus, Proposition 3-2 is proved.

Proposition 3-3. In the RC model, the two manufacturers' optimal wholesale prices $w_{r c 1}^{*}$ and $w_{r c 2}^{*}$ can be obtained respectively as

$$
\begin{aligned}
& w_{r c 1}^{*}=F_{1}-F_{2} p_{r c 1}^{*}-F_{3} p_{r c 2}^{*} \\
& w_{r c 2}^{*}=F_{4}-F_{5} p_{r c 2}^{*}-F_{6} p_{r c 1}^{*}
\end{aligned}
$$

where $p_{r c 1}^{*}$ and $p_{r c 2}^{*}$ are defined as in Proposition 3-2.

Proof. From Propositions 3-1 and 3-2, it can be seen that Proposition 3-3 holds.

With Propositions 3-2 and 3-3, Proposition 3 can be obtained.

\section{References}

1. Tsai, S.-B.; Wei, Y.-M.; Chen, K.-Y.; Xu, L.; Du, P.; Lee, H.-C. Evaluating Green Suppliers from Green Environmental Perspective. Environ. Plan. B-Plan. Des. 2016, 43, 941-959. [CrossRef]

2. Liu, B.; Li, T.; Tsai, S. Low carbon strategy analysis of competing supply chains with different power structures. Sustainability 2017, 9, 835. [CrossRef]

3. Qu, Q.; Tsai, S.; Tang, M.; Xu, C.; Dong, W. Marine ecological environment management based on ecological compensation mechanisms. Sustainability 2016, 8, 1267. [CrossRef]

4. Choi, C. Price competition in a channel structure with a common retailer. Mark. Sci. 1991, 10, 271-296. [CrossRef]

5. Choi, T.M.; Li, Y.; Xu, L. Channel leadership, performance and coordination in closed loop supply chains. Int. J. Prod. Econ. 2013, 146, 371-380. [CrossRef]

6. Szmerekovsky, J.; Zhang, J. Pricing and two-tier advertising with one manufacturer and one retailer. Eur. J. Oper. Res. 2009, 192, 904-917. [CrossRef]

7. Zhao, J.; Tang, W.; Zhao, R.; Wei, J. Pricing decisions for substitutable products with a common retailer in fuzzy environments. Eur. J. Oper. Res. 2012, 216, 409-419. [CrossRef]

8. Yue, X.; Mukhopadhyay, S.; Zhu, X. A Bertrand model of pricing of complementary goods under information asymmetry. J. Bus. Res. 2006, 59, 1182-1192. [CrossRef]

9. Wang, Y. Joint pricing-production decisions in supply chains of complementary products with uncertain demand. Oper. Res. 2006, 54, 1110-1127. [CrossRef]

10. Cho, S.; McCardle, K.; Tang, C. Optimal Pricing and Rebate Strategies in a Two-Level Supply Chain. Prod. Oper. Manag. 2009, 18, 426-446. [CrossRef]

11. Ingene, C.; Parry, M. Channel coordination when retailers compete. Marketing Science 1995, 14, 360-377. [CrossRef]

12. Tsay, A.; Agrawal, N. Channel conflict and coordination in the e-commerce age. Prod. Oper. Manag. 2004, 13, 93-110. [CrossRef]

13. Zhang, J.; Chen, J.; Lee, C. Coordinated pricing and inventory control problems with capacity constraints and fixed ordering cost. Nav. Logist. Res. 2012, 3, 376-383. [CrossRef]

14. Haruvy, E.; Li, T.; Sethi, S. Two-stage pricing for custom-made products. Eur. J. Oper. Res. 2012, 219, 405-414. [CrossRef]

15. Li, S.; Zhang, J.; Tang, W. Joint dynamic pricing and inventory control policy for a stochastic inventory system with perishable products. Int. J. Prod. Res. 2015, 53, 2937-2950. [CrossRef]

16. Chan, L.; Shen Max, Z.; Simchi-Levi, D.; Swann, J. Coordination of pricing and inventory decisions: A survey and classification. In Handbook of Quantitative Supply Chain Analysis: Modeling in the E-Business Era; Simchi-Levi, D., Wu, S., Shen Max, Z., Eds.; Kluwer: Boston, MA, USA, 2004.

17. Bhaskaran, R.; Gilbert, S. Selling and leasing strategies for durable goods with complementary products. Manag. Sci. 2005, 51, 1278-1290. [CrossRef] 
18. Mukhopadhyay, S.; Yue, X.; Zhu, X. A Stackelberg model of pricing of complementary goods under information asymmetry. Int. J. Prod. Econ. 2011, 134, 424-433. [CrossRef]

19. Yin, S. Alliance formation among perfectly complementary suppliers in a price-sensitive assembly system. Manuf. Serv. Oper. Manag. 2010, 12, 527-544. [CrossRef]

20. Dong, L.; Narasimhan, C.; Zhu, K. Product line pricing in a supply chain. Manag. Sci. 2009, 55, $1704-1717$. [CrossRef]

21. Wei, J.; Zhao, J.; Li, Y. Pricing decisions for complementary products with firms' different market powers. Eur. J. Oper. Res. 2013, 224, 507-519. [CrossRef]

22. Greene, D. JVS, alliances, consortia on path to survival for many. Semicond. Mag. 2002, 3, 1216.

23. Li, J.; Wang, S.; Cheng, T. Competition and cooperation in a single-retailer two-supplier supply chain with supply disruption. Int. J. Prod. Econ. 2010, 124, 137-150. [CrossRef]

(C) 2018 by the authors. Licensee MDPI, Basel, Switzerland. This article is an open access article distributed under the terms and conditions of the Creative Commons Attribution (CC BY) license (http://creativecommons.org/licenses/by/4.0/). 